\title{
Okul öncesi eğitimde yardımcı öğretmenlik mesleği
}

\section{Assistant teaching profession in preschool education}

\begin{abstract}
Makale Geçmişi
Geliş : : 6 Eylül 2019

Düzeltme : 13 Mart 2020

Kabul : 16 Mart 2020
\end{abstract}

\section{Makale Türü}

Derleme Makale

\section{Article History}

Received : 6 September 2019

Revised : 13 March 2020

Accepted : 16 March 2020

\section{Article Type}

Review Article

\section{Mehmet Oğuz Göle ${ }^{1}$, Alper Yusuf Köroğlu²}

Öz: Okul öncesi öğretmenliği, diğer meslek grupları gibi, profesyonel bir meslektir. Yardımc öğretmenlik de eğitim öğretim faaliyetlerinde öğretmene destek sağlayacak profesyonel bir meslek olarak ele alınmalıdır. Ülkemizdeki okul öncesi kurumlarında yardımcı öğretmenlik uygulamalarının çok fazla olmaması ve resmi ana okullarda kanunen zorunluluğun bulunmamasından dolayı yardımc1 ögrretmenlikle ilgili yapılan çalışmaların çok az olduğu görülmektedir. Bu nedenle de makalede, yardımcı öğretmenlikle ilgili ülkemizde yapılabilecek olası çalışmalara sşık tutması ve böyle bir mesleğin okul öncesi eğitim kurumlarında hizmet vermesi durumunda, yardımcı öğretmenlerin görev ve sorumlulukları, öğretmen ile yardımcı öğretmen arasındaki ilişki ve bunun eğitim ortamına etkileri, yardımc1 öğretmenin eğitim düzeyi, öğretmen-çocuk oranı, yardımcı öğretmenin denetimi ve değerlendirilmesi konularında literatür ışı̆̆ında bilgi verilmeye çalıșılmıştır.

Anahtar Kelimeler: Yardımcı öğretmenlik, Okul öncesi eğitim, Anaokulu,

Abstract: Preschool teaching is a professional profession like other professional groups. Assistant teaching should also be considered as a professional profession that will provide support to the teacher in educational activities. In preschool institutions in our country, it is seen that there are very few studies on assisting teachers due to the fact that there is not much assistant teaching practices and there is no legal obligation in official kindergartens. For this reason, in the article, if it sheds light on possible studies related to assistant teachers in our country and such a profession serves in preschool education institutions; The duties and responsibilities of assistant teachers, the relationship between teacher and assistant teacher and its effects on educational environment, the level of education of the assistant teacher, teacher-child ratio, supervision and evaluation of the assistant teacher were tried to be given in the light of literature.

Keywords: Assistant teacher, Preschool education, Kindergarten

${ }^{1}$ Afyon Kocatepe Üniversitesi, Afyon Meslek Yüksekokulu, Çocuk Gelişimi Programı, moguzgole@gmail.com, ORCID: 0000-0003-2826-1790 2 Karamanoğlu Mehmetbey Üniversitesi, Sağlık Hizmetleri Meslek Yüksekokulu, Çocuk Gelişimi Programı, aykoroglu@gmail.com, ORCID:00000002-8131-0021

Atıf için/To cite this article:

Göle, M. O. \& Köroğlu, A. Y. (2020). Okul öncesi eğitimde yardımcı öğretmenlik mesleği. Erken Çocukluk Çalıs̆maları Dergisi, 4(1), 222-238. doi: http://dx.doi.org/10.24130/eccd-jecs.1967202041190 


\section{SUMMARY}

\section{Introduction}

Preschool teaching is a professional profession like other professional groups. Assistant teaching should also be considered as a professional profession that will provide support to the teacher in educational activities. In preschool institutions in our country, it is seen that there are very few studies on assisting teachers due to the fact that there is not much assistant teaching practices and there is no legal obligation in official kindergartens. For this reason, in the article, if it sheds light on possible studies related to assistant teachers in our country and such a profession serves in preschool education institutions; The duties and responsibilities of assistant teachers, the relationship between teacher and assistant teacher and its effects on educational environment, the level of education of the assistant teacher, teacher-child ratio, supervision and evaluation of the assistant teacher were tried to be given in the light of literature.

\section{Duties and Responsibilities of Assistant Teachers}

Traditionally, when two teachers are present in a classroom, the position of the educators is determined as the leading teacher and the assistant teacher. The assistant teacher is seen as an important part of the education team. (S)he works under the leadership of the leading teacher to ensure that children can make the most of their learning opportunities. Assistant teachers work differently depending on the support of children and their needs. (S)he supports the leading teacher responsible for children's learning and behavior in these matters. The presence of an assistant teacher who provides teaching support to children also changes the role of teachers. In pre-school education; As it is a program integrated with education and care, it is seen that the role distinction between teachers and assistant teachers is more severe. The work of the assistant teacher in daily activities can vary greatly from one class to another. While there is a clear division of labor between some assistant teachers and the teacher, some of the tasks they do have a significant partnership.

\section{Relationship Between Teacher and Assistant Teacher and Its Effects on Educational Environment}

The partnership between the assistant teacher and the teacher is associated with the highest grade quality. Teamwork or coordination between the assistant teacher and the teacher, supervision of the assistant teacher by the teacher positively affects the formation of a positive learning environment in the classroom and therefore the success and development of the children. Assistant teachers who work in collaboration with the teacher make valuable contributions to the classes.

\section{Training Level of Assistant Teachers}

In most public and private schools and child care centers, there are different recruitment criteria for the education and experience of teachers and assistant teachers. Therefore, in general, it is expected that teachers will be more competent in teaching practices and show more correct teacher behaviors than assistant teachers because of their high level of education and experience in formal education. The level of education required for the assistant teacher may vary depending on the country, approach and institution. So that an 
assistant teacher working in the institution can continue high school education, high school diploma or high school diploma must have a certificate that is equivalent.

\section{Teacher-child ratio}

Determination of teacher-child ratio is seen as an important element affecting the quality of preschool education. Teacher-child ratios should be determined and paid attention to in order to ensure better quality of preschool education practices. The second staff in the classroom varies according to the approaches. These staff can sometimes be co-teachers with the same educational level and the same duties and responsibilities, and sometimes they are assistant teachers.

\section{Supervision and evaluation of the assistant teacher}

Educators often supervise assistant teachers, and a manager assumes the assessment of assistant teachers. The supervisor of the assistant teacher should be able to work as part of a team and be capable of being a professional part of the teaching team. Trust, communication, precise roles, directing, sharing goals and feedback are among the features that should be in a teaching team. Teachers may not have sufficient knowledge and skills to supervise assistant teachers. In-service trainings on this subject will be useful for improving the performance of the help teachers.

\section{Conclusions and recommendations}

It is seen that this practice does not take place in public institutions yet in our country, but there are differences in private institutions but it is applied from time to time. However, it is seen that this situation does not apply to assistant teachers while defining the duties and responsibilities of other personnel, and different definitions are made.

In the light of literature information; It is seen that the education level of the assistant teachers should be at least secondary education or associate degree level or they should have certificate about child development field.

The duties and responsibilities of assistant teachers are education process, assessment, family participation, meeting the care and needs of children and other tasks.

However, since there is no clear practice in our country, the opinions of preschool teachers and administrators about auxiliary teaching should be investigated. 


\section{GİRIŞ}

Meslek; bir işe girmek isteyen bireyin o işi iyi bildiği ve gerekli niteliklere sahip olduğu anlamına gelmektedir. Eğer meslek bir öğrenme süreciyle elde edilmişse, insanların işlerini yapmak ve işlerine çözüm bulmak için kullanılan bilgi ya da var olan bilgi üzerine kurulu olan sanatı ifade etmektedir (Cirhinlioğlu, 1996). Yapılacak olan meslek için çeşitli özelliklere sahip olunması gerekmektedir. Bayles'e göre bir meslek için gerekli olan özellikler; kapsamlı bir eğitim alma, entelektüel bileşenlere sahip olma ve toplum için önemli bir hizmet verecek pozisyonda olmadır (Akt: Wueste, 1994).

Öğretmenlik bir meslektir. Profesyoneller olarak öğretmenler, her gün ders boyunca zor ve kesinlikle kıymetli kararlar alırlar; böylece tüm öğrencilerin akademik, duygusal ve sosyal potansiyellerine ulaşmalarını sağlamaktadırlar (Glenn, Moos ve Schwab, 2005). Öğretmenlik, eğitim sektöründe yer alan sosyal, kültür, ekonomi, bilim ve teknoloji boyutlarına sahip, alanıyla ilgili uzmanlık ve beceriyi temel alan, mesleğiyle ilgili gerekli formasyona sahip, profesyonel bir uğraşı alanıdır (Gürkan, 2007). Bu durumda okul öncesi öğretmenliği de diğer öğretmenlik branşları gibi, profesyonel meslek gruplarından birisidir.

İnsanlar, maddi kaygılar nedeniyle ya da mesleki çekicilikten dolayı okul öncesi öğretmenliğini seçmemektedir. Çünkü çocuklarla çalışmak sabır istemekte ve en az sevimli olanlar dahil başkalarının çocuklarıyla ilgilenmek için istekli olmak gerekmektedir. Okul öncesi öğretmeni olmak, en zorlayıcı durumlarda bile tamamıla tatmin edici bir iştir (Colker, 2008). Yapılan çalışmalar ülkemizde öğretmen adaylarının \%48 oranla bu mesleği sevdiği için öğretmenliği tercih ettiğini, okul öncesi öğretmenliği bölümünü tercih eden adayların $\% 34.6, \% 57.5$ ve $\% 77$ gibi değissen oranlarda üniversiteye başlamadan önceki ideal mesleklerinin de öğretmenlik olduğunu yani öğretmen olmak istediklerini, ayrıca öğretmen adaylarının \%31.3'ü de iş garantisi ve çalışma koşuları nedeniyle okul öncesi öğretmenliğini tercih ettiklerini, \%81.8’inin de okudukları bölümden memnun olduğunu, \%86'sının öğretmen olarak çalıştığında başarılı ve verimli olacağını düşündüğünü, \%84.1'inin KPSS olmasa bile öğretmen olarak çalışacağını göstermektedir. (Aslan ve Köksal Akyol, 2006; Aysu, 2007; Bursal, 2016; Çevik ve Yiğit, 2009). Okul öncesi öğretmenliğinin de birçok sorumluluğu bulunmaktadır. Çünkü eğitim verdiği çocuklar bağımsızlığını tam olarak kazanamamış, bir yetişkine ihtiyaç duyan bireylerdir. Okul öncesi öğretmeninin, çocukların sevgi, şefkat, ilgi ve beslenme gibi temel ihtiyaçlarının farkında olarak öncelikle bu ihtiyaçlarını karşılaması ve yapacağı çalışmaları çocukların gelişim seviyelerini dikkate alarak planlaması gerekmektedir (Zembat, 2007).

Yardımcı öğretmen teriminin tanımlanmasının her zaman karmaşık bir iş olduğu ve bu konuda birçok tartışmanın var olduğu görülmektedir. Yardımcı öğretmen dışında, öğrenim destekçisi, sınıf yardımcısı ve özel ihtiyaç yardımcısı gibi bir dizi başlık kullanılmaktadır. Yardımcı öğretmen 
rolünün somut bir tanımının olmaması, okulların rolleri belirleme esnekliğini getirmektedir. $\mathrm{Bu}$ esneklik yardımcı öğretmenin uygun şekilde görevlendirmesine izin vermesine rağmen, iş tanımlanmasında ve yönetim tarafindan farklı beklentilerin oluşmasına neden olmaktadır. Aynı zamanda öğretmenler ve yardımcı öğretmenler arasındaki, öğrenme ve öğretme görev sınırının net olmadığ1 da belirtilmektedir (Basford, Butt ve Newton, 2017).

Yardımcı öğretmenler çocuklara veya ailelere doğrudan hizmet sağlayan okullarda çalışan kişilerdir. Yardımcı öğretmenler, öğretmenlerin veya diğer profesyonel çalışanların gözetimi altında; çocukların öğrenmesi için planlama, uygulama ve değerlendirme yapmakta, öğretim programının çocuklar üzerindeki etkililiğini değerlendirmektedirler (Pickett, 1999). Bir okul öncesi eğitim sınıfinda yardımcı öğretmen genellikle sınıfta özel gereksinimli çocuk olduğu zaman bulunduğu belirtilmektedir. Fakat sınıfta özel gereksinimli bir çocuğun olup olmaması, yardımcı öğretmenin sınıfta bulunmasını etkileyen tek etmen değildir. Sınıftaki hem özel gereksinimli çocukların hem de tipik gelişim gösteren çocukların ihtiyaçları ne olursa olsun personel-çocuk oranı standartlarına uyulması gerekmektedir. Bu durum da yardımcı öğretmenlerin okul öncesi eğitim sınıflarında bulunmasının tek nedene bağlı olarak değil de her zaman sınıflarda bulunabileceğini göstermektedir (Sosinsky ve Gilliam, 2011).

Öğretmenlerin eğitimi ve öğretimi hakkında birçok şey bilinmesine rağmen, yardımcı öğretmenlerin eğitimi hakkında çok az bilgi bulunmaktadır. Yardımcı öğretmenler hakkında genel olarak bilinen şey öğretmenlerden daha düşük eğitim seviyesine sahip olduklarıdır (Sosinsky ve Gilliam, 2011; Finn ve Pannozzo, 2004). Yardımcı öğretmen, okul öncesi eğitim ortamlarında bir veya daha fazla öğretmene yardım sağlamaktadır. Yardımcı öğretmenlerin yerine getirecekleri görevler, rol beklentileri ve eğitimleriyle ilgili dünya genelinde farkll1ıklar olduğu görülmektedir. Örnek olarak, son yıllarda Amerika Birleşik Devletleri'nde okul öncesi eğitim kurumlarında çalışan yardımcı öğretmenlerden çocuklara beceri öğretmeleri beklenmektedir. Finlandiya'da ise çocukların gelişimini desteklemesi ve öğrenmelerini yönlendirmek için uygun ortamın nasıl hazırlanacağıyla ilgili bilgileri edinmeleri için yardımcı öğretmenlere eğitim verildiği görülmektedir Jones, Ratcliff, Sheehan ve Hunt, 2012). Ülkemizde ise resmi kurumlarda yardımcı öğretmenlik uygulaması bulunmamakta ve bazı özel kurumlar ise bu uygulamayı kendi işleyişleri doğrultusunda yapabilmektedir.

Okul öncesi eğitim kurumlarında farklı görev ve sorumlulukları bulunan personeller yer almaktadır. Okul müdürü, müdür yardımcısı, okul öncesi öğretmeni, rehber öğretmen, aşçı, temizlik görevlileri ve yardımcı öğretmen bunlar arasında gösterilebilir. İlgili literatür incelendiğinde, yardımcı öğretmenliğin rolü, sorumlulukları, görevleri ve diğer özellikleri hakkındaki bilgilerin net bir şekilde 
belirlenmesi gerektiği görülmektedir. Öyle ki Yılmaz (2011); bir süre ABD’de yardımcı öğretmen olarak çalışan Türk bir katılımcıyla yaptığı çalışmasında, katılımcının sınıflarda öğretmen ile yardımcı öğretmenin görev ve sorumlulukları arasında net bir sınır bulunmadığı, bu durumun da öğretmenle yardımcı öğretmen arasında rekabete ve çocukların davranışları konusunda karışıklığa sebebiyet verdiği görüşünde olduğunu ifade etmiştir. Köroğlu ve Göle (2020); ülke genelinde resmi okul öncesi eğitim kurumlarında çalışan 748 öğretmenle yaptıkları çalışmada öğretmenlerin \%97.5’inin okul öncesi eğitim sınıflarında yardımcı öğretmenleri zorunlu bir ihtiyaç olarak gördüğünü belirtmiştir. Ancak ülkemizdeki özel okul öncesi kurumlarında yardımcı öğretmenlik uygulamaları çok fazla olmamakla birlikte, resmi okul öncesi eğitim kurumlarında kanunen zorunluluk bulunmamaktadır. Bundan dolayı okul öncesi eğitim kurumlarında yardımcı öğretmenlikle ilgili yapılan çalışmaların da az sayıda olduğu görülmektedir. Bu nedenle de makalede, yardımcı öğretmenlikle ilgili ülkemizde yapılabilecek olası çalışmalara 1şık tutması ve böyle bir mesleğin okul öncesi eğitim kurumlarında hizmet vermesi durumunda, yardımcı öğretmenlerin görev ve sorumlulukları, öğretmen ile yardımcı öğretmen arasındaki ilişki ve bunun eğitim ortamına etkileri, yardımcı öğretmenin eğitim düzeyi, öğretmen-çocuk oranı, yardımcı öğretmenin denetimi ve değerlendirilmesi konularında literatür ışığında bilgi verilmeye çalışılmıştır.

\section{Yardımcı Öğretmenlerin Görev ve Sorumlulukları}

Geleneksel olarak, bir sınıfta iki öğretmen bulunduğunda, eğitimcilerin pozisyonu lider öğretmen ve yardımcı öğretmen olarak belirlenmektedir. Yardımcı öğretmen, eğitim takımının önemli bir parçası olarak görülmektedir. Çocukların, öğrenme firsatlarından en iyi şekilde faydalanmalarını sağlamak için lider öğretmenin yönetimi altında çalışmaktadır. Yardımcı öğretmenler çocukların desteklenmesi ve onların ihtiyaçlarına bağlı olarak farklı şekilde çalışmaktadır. Çocukların öğrenmesi ve davranışlarından sorumlu olan lider öğretmene bu konularda destek olmaktadır. Çocuklara öğretim desteği sağlayan bir yardımcı öğretmenin varlığı öğretmenlerin de rollerini değiştirmektedir. Bazı öğretmenler bu durumla karşılaştıklarını ve çocuklara gerekli olan kişisel yardımı sağlayamadıklarını belirtmektedir. Okul öncesi eğitimde; eğitim ve bakım ile bütünleşen bir program olmasından dolayı öğretmen ve öğretmen yardımcıları arasındaki rol ayrımının daha katı olduğu görülmektedir. Yardımcı öğretmenin günlük faaliyetler içerisinde çalışmaları, bir sınıftan diğer sınıfa büyük ölçüde değişebilmektedir. Bazı yardımcı öğretmen ve öğretmen arasında net bir iş bölümü varken, bazılarının yaptıkları görevler önemli ölçüde ortaklık göstermektedir (French ve Gerlanch, 1999; NAEYC, 2008b; New Zealand Government Ministry of Education, 2012; Shim, Hestenes ve Cassidy, 2004; WhitebookGomby, Bellm, Sakai ve Kipnis. 2009). 
Literatür incelendiğinde, yardımcı öğretmenlerin görev ve sorumluluklarına ilişkin bilgiler şu şekilde özetlenebilir (French ve Gerlanch, 1999; Michigan State Board of Education, 2017; NAEYC, 2008a; NAEYC, 2017a; NAEYC, 2017b; New York City Department of Education, 2016; New Zealand Government Ministry of Education, 2012; Oklahoma Child Care Services, 2018; Pickett, 1999; Puget Sound Educational Service District, 2007):

- Çocuklarla öğrenme faaliyetlerini yürütmek,

- Çocukların davranışlarını yönetmesi için stratejiler kullanarak lider öğretmene yardımcı olmak,

- Çocukların birbirleriyle çalışması ve birbirlerinden öğrenmesini teşvik etmek,

- Lider öğretmenin bir çocukla doğrudan çalışabilmesi için diğer çocuklarla ilgilenmek,

- Sabırlı olmaları ve öğretmenin istediği şekilde çocuklara eğitim vermek,

- Eğitim sürecinde ortaya çıkan boşlukları doldurmak,

- Bireysel ve küçük gruplara öğretmenler tarafindan geliştirilen planları ve stratejileri uygulamak,

- Çocukların davranışları ve performansları ile ilgili bilgileri belgeleme ve öğretmenlerin gözetiminde çocukları değerlendirme çalışmalarına katılmak,

- Öğretmenin geliştirdiği davranış yönetimi ve disiplin ile ilgili yöntemleri uygulamak,

- Materyalleri hazırlamak ve öğrenme merkezini düzenlemek,

- Ailelerin, çocukların eğitimine katılması konusunda öğretmene yardımcı olmak,

- Öğretmen tarafindan yapılan etkinlikler sırasında ve çocukların bağımsız etkinliklerinde çocukları gözlemlemek ve onlara yardımcı olmak,

- Öğretmenin yönlendirdiği eğitim sonrasında eğitimin devam etmesini sağlamak,

- Gerekli materyalleri hazırlayarak eğitim programını desteklemek,

- Büro ile ilgili işleri yapmak,

- Çocukları oyun salonu ve otobüs binme alanında izlemek,

- Çocukların gelişim düzeyini ve öğrenme gereksinimleri belirlenmesi için öğretmenlere değerlendirme konusunda yardımcı olmak,

- Öğretmenlerin hazırladığı oyun ve çocukların yaşına uygun etkinliklerle, çocukların sosyal ve iletişim becerilerinin, özgüvenin, yaratıcıllğının gelişmesini kolaylaştırmak,

- Farklı gereksinimi olan çocukların eğitime katılmasını ve eğitiminin desteklenmesi için uygun ortamın hazırlanması konusunda öğretmene yardımcı olmak, 
- Çocukların bireysel ve grup öğrenme deneyimlerinin planlanması için bilgilerin paylaşıldı̆̆ı düzenli toplantılarla öğretmenle görüşmek,

- Gelişimsel olarak hazırlanan etkinliklere çocukların katılımını sağlamak için program uygulama ekibi tarafindan alınan kararları uygulamak,

- Ailelerin, çocukların öğrenmelerine ve öğrenme ortamlarına katılımlarına yardımcı olmak ve toplumsal kaynaklara ve hizmetlere ulaşmaları için gerekli olan bilgiyi ve yardımı sağlamak,

- Gerekli durumlarda bireyselleştirilmiş aile hizmet planı ve bireyselleştirilmiş eğitim planı toplantılarına katılmak,

- Kıyafet çıkarma, vücut temizliği ve giyinme gibi konularda mahremiyet ilkeleri doğrultusunda yardıma ihtiyacı olan çocuklara yardım etmek,

- Yemeğine hazırlık ve yemek sırasında çocukları yalnız bırakmamak için öğretmenle aşamalı olarak çocukların yanında olmak,

- Otantik değerlendirme çalışmalarına katılarak portfolyo hazırlanmasında öğretmene yardımc1 olmak,

- Oyuna katılma, oyunu sürdürme ve oyunu geliştirme konularında yardımcı olarak çocukların sosyal becerileri uygulamasını ve arkadaşlık kurmalarını desteklemek,

- Özel gereksinimli çocukların için uygulanacak öğretim yaklaşımlarının uygulanmasına öğretmen, özel eğitim öğretmeni ve yardımcı öğretmen bir ekip halinde çalışmak,

- Yardımcı öğretmenlerin yemek hazırlama ve masa silmek gibi öğretim dışı rolleri de bulunmaktadır.

Yukarıdaki bilgiler ışığında belirtilen davranışlar yalnızca öğretmene ait değil yardımcı öğretmeni de kapsamaktadır. Yardımcı öğretmenlikle ilgili diğer bilgilerde de sınıf içerisinde sağlıklı bir işleyişin sağlanabilmesi için öğretmen ve yardımcı öğretmenin görev ve sorumluluklarının net bir şekilde ayrılması gerektiği belirtilmektedir. Bununla birlikte öğretmen ve yardımcı öğretmenlerin eğitim ekibinin bir parçası olarak iş birliği içinde çalışmaları, iletişim ve ilişki kurma becerilerinde yeterli ve uzmanlaşmış olmaları, bu konularda mesleki gelişim eğitimleri almaları bu ekibin uyumlu bir şekilde çalışmasına katkı sağlayabilmektedir.

Köroğlu ve Göle (2020); okul öncesi eğitim kurumlarında yardımcı öğretmenlerin görev ve sorumluluklarına ilişkin öğretmen görüşleri üzerine yaptıkları çalışmada, çocukların gelişimine ve güvenliğine uygun bir öğrenme ortamının oluşturulmasında, planlanan etkinliklerin uygulanmasında, öğrenme materyallerinin hazırlanmasında, öğrenme merkezlerinin düzenlenmesinde, günlük rutinlerde öğretmene yardımcı olma, kıyafet çıkarma, beden temizliği ve 
giyinme konusunda çocuklara yardımcı olma, yemeğe hazırlık ve yemek zamanlarında, uyku zamanında öğretmenle nöbetleşe şekilde çocukların yanında durma gibi eylemlerin öğretmenler tarafından yardımcı öğretmenlerin öncelikli görev ve sorumlulukları arasında görüldüğünü belirtmişlerdir.

\section{Öğretmen ile Yardımcı Öğretmen Arasındaki İlişki ve Bunun Eğitim Ortamına Etkileri}

Çocukların sınıftaki yetişkinlerle etkileşimini inceleyen araştırmalar, onların büyük kısmının önemli, etkili ilişkiler kurduğu ve katılım sağladığ kişinin öğretmen olduğunu belirtmektedir. Bu da sınıftaki etkili kişinin öğretmen olduğunun makul bir göstergesidir. Öğretmen-çocuk etkileşimi ve program kalitesi arasındaki ilişkiyi inceleyen araştırmalar, tek öğretmenli sınıflarla iki öğretmenli sınıflar arasındaki öğretmen-çocuk etkileşimlerinin niteliğine çok az odaklanmaktadır. İki öğretmenli sınıflardaki öğretmenler ve çocuklar arasında etkileşimlerin, öğretmenlerin farklı sorumlulukları ve ikinci bir öğretmenden (sınıf yönetimi ve programın planlaması açısından) alacakları desteklerden dolayı, tek öğretmenli sınıflara göre daha farklı olacağı düşünülmektedir. Öğretmen-çocuk oranı aynı olsa da sınıfta başka bir öğretmenin olması, tek bir öğretmenin sunmakta zorlandığı pedagojik desteği ve olumlu ilişkiyi sağlayabilmektedir. Benzer şekilde, tamamlayıcı etkileşim davranışları sağlayan birden çok öğretmenin olması çocuğa fayda sağlamaktadır. Çünkü her ne kadar öğretmen sınıftaki tüm çocukların öğrenmesinden ve davranışlarında birinci öncelikle sorumlu olsa da çocuklar yalnızca yardımcı öğretmen tarafından desteklenmemekte sınıf öğretmeni ve yardımcı öğretmenle birlikte desteklenmektedir. Ayrıca yardımcı öğretmen; planlama ve gözden geçirme sürecine dahil olduğunda, öğretmenlerle düzenli olarak bir araya geldiklerinde, iyi uygulamaların paylaşılması için firsatlar sağlandığında yardımcı öğretmenler ile öğretmen arasında güçlü çalışma ilişkileri geliştirilmektedir. Bu bağlamda öğretmen ve öğretmen yardımcısı arasında etkili bir iş birliği olduğu zaman hem yetişkinlerin hem de çocukların farklı bakış açıları kazanarak problemleri birlikte çözme konusunda faydalı olduğu görülmektedir (Ferguson, 2014; NAEYC, 2008a; Newzealand Governmen Ministry of Education, 2012; Ratcliff, Jones, Vaden, Sheen, Hunt., 2011; Shim, Hestenes ve Cassidy, 2004).

Özel gereksinimli çocuklara destek sağlamak için çalışan yardımcı öğretmenlerle ilgili yapılan araştırmalarda genellikle serbest zamana değinilmektedir. Serbest zaman saatleri, öğretmenlerin uygun ve ilgi çekici etkinlikler geliştirmelerini, zaman ve kaynakları etkili bir şekilde kullanmalarını ve çocukların bireysel amaç ve hedefleri ele almalarına yardımcı olmayı amaçlamaktadır. Kaliteli uygulama kriterleri arasında etkinliklerin önceden planlaması için uygun bir süre ayrılması da bulunmaktadır. Fakat planlama zamanında öğretmenler gözlemlendiğinde, zamanlarının çoğunu 
eğitim ve öğretim için harcamak yerine materyal hazırlama gibi faaliyetlere harcadıkları görülmektedir (Grisham-Brown ve Pretti-Frontczak, 2003; Sosinsky ve Gilliam, 2011).

Yardımcı öğretmen ve öğretmen arasındaki ortaklık, en yüksek sınıf kalitesiyle ilişkilendirilmektedir. Yardımcı öğretmen ve öğretmen arasındaki takım çalışması veya koordinasyon, yardımcı öğretmenin öğretmen tarafindan denetlenmesi sınıfta olumlu öğrenme ortamının oluşmasına ve bundan dolayı çocukların başarısına ve gelişimine olumlu olarak etki etmektedir. Öğretmenle iş birliği içinde çalışan yardımcı öğretmenler sınıflara değerli katkılarda bulunmaktadır. Öğretmenler öğrenme deneyimlerinin, süresini, amacını planlarken, aynı zamanda çocukların ilgilerini, yaşını, önceki bilgilerini ve yeteneklerini dikkate almaları gerekmektedir. Yardımcı öğretmenler, öğretmenlerin bu yaklaşımlarını desteklerken, bunlarla ilgili çeşitli stratejiler kullanmalarını önerebilmektedir. Bu stratejileri kullanırken öğrenmenin zenginleşmesi ve deneyimlerin arttırılmasını sağlamaktadır (Departmen of Education of Training Queensland Goverment, 2015; Sosinsky ve Gilliam, 2011).

\section{Yardımcı Öğretmenlerin Eğitim Düzeyi}

Resmi ve özel okulların çoğunda ve çocuk bakım merkezlerinde, öğretmen ve yardımcı öğretmenlerin eğitimi ve deneyimi alanlarında farklı işe alım kriterleri bulunmaktadır. Bu nedenle, öğretmenlerin eğitim seviyelerinin ve deneyim düzeylerinin yüksek olması nedeniyle öğretmenlik uygulamalarında daha yetkin olması ve yardımcı öğretmenlerden daha doğru öğretmen davranışları sergilemesi beklenmektedir. Ancak yardımcı öğretmenlerin oldukça karmaşık görevleri yerine getirme yükümlülükleri olduğu ve bu görevleri yerine getirmek için belirli bir beceri ve eğitime ihtiyaç duyulduğu belirtilmektedir. Yardımcı öğretmen için gerekli olan eğitim düzeyi ülkeye, yaklaşıma ve kuruma göre farklılaşabilmektedir. Öyle ki kurumda çalışan bir yardımcı öğretmen lise eğitimine devam edebilmekte, lise diploması ya da lise diplomasıyla denkliği olan bir belgesi olması gerekmektedir (Butt ve Lowe, 2012; Oklahoma Department of Human Services Child Care Services, 2018; Shim, Hestenes ve Cassidy, 2004).

Amerika Birleşik Devletleri’ndeki yardımcı öğretmenlerin eğitim düzeylerine ilişkin uygulama örnekleri incelendiğinde görülüyor ki; Head Start Programı'nda yardımcı öğretmenin, en az çocuk gelişimci belgesi, lisans veya ön lisans programına ya da 2 yıl içinde tamamlayacağı bir çocuk gelişimi programına kayıtlı olması gerekmektedir. Michigan ve New Hampshire eyaletlerinde yardımcı öğretmenlerin erken çocukluk eğitimi veya çocuk gelişimi alanında ön lisans derecesine sahip olmaları gerekmektedir. Çünkü ön lisans derecesi, okul öncesi eğitimde etkili ekip öğretmenleri olmak için eşit ve sistematik olarak hazırlayan resmi eğitim seçenekleri olarak görülmektedir. New 
Jersey eyaletinde yardımcı öğretmenlerin tamamı lise diplomasına veya dengi bir sertifikaya sahip olmaları gerekmektedir. Bazı eyaletlerde yardımcı öğretmenlikte iş deneyimi de aranabilmektedir. Örneğin Arizona'da 12 aylık bir çalışma ya da birçok bakım merkezinde 12 ay boyunca gönüllü olarak hizmet verme gibi özellikler aramaktadır. Bunun yanında bazı eyaletler de yardımcı öğretmen eğitimi konusunda projeler geliştirmektedir. Örneğin Nebraska eyaletinde yardımcı öğretmenler için Project PARA isimli proje geliştirilmiştir. Bu proje yardımcı öğretmenlerin sınıf eğitimlerini etkili bir şekilde pekiştirmek için gerekli temel bilgi ve becerileri geliştirmeye yardımcı olacak web tabanlı bir eğitim programıdır. National Association for the Education of Young Children (Ulusal Küçük Çocukların Eğitimi Derneği)'a göre yardımcı öğretmen en az lise diplomasına sahip olması ve aynı zamanda kurumda bulunan yardımcı öğretmenlerin yarısı çocuk gelişimi ön lisans diplomasına sahip olması gerekmektedir. Çocuk gelişimi ön lisans diplomasına sahip olmayan yardımcı öğretmenler, çocuk gelişimi ön lisans programına kayıt olması, aktif olarak eğitim görmesi gerekmekte veya eş değerinde bir programda devam etmesi gerekmektedir (Arizona Department of Health Services, 2010; Michigan State Board of Education, 2017; NAEYC, 2017b; Nebraska Department of Education, 2017; New Hampshire Department of Health and Human Services, 2017; New Jersey Department of Education, 2015; U.S. Deparment of Healt and Human Services, 2019).

Yapılan araştırmalar gösteriyor ki; öğretmen ve yardımcı öğretmen arasındaki eğitim seviyesi farkı öğretim ve planlama görevlerini etkilemektedir. Öğretmenler; yardımcı öğretmenlerle aralarındaki eğitim seviyesinin az olmasının yardımcı öğretmenlerin görevlerinde önemli bir rol oynadığ1 belirtmektedir. Ancak tutarsızlığın en yüksek olduğu durum, öğretmenin lisans veya yüksek lisans derecesine sahip olması ve yardımcı öğretmenin lise diplomasına sahip olması olarak gösterilmektedir. Bu durumda öğretmenler; yardımcı öğretmenlerin öğretim görevlerinde daha az önemli rol oynadığını belirtmektedir (Bellm, Burton, Whitebook, Broatch ve Young, 2002).

$\mathrm{Bu}$ bağlamda yardımcı öğretmenler, çocuk gelişimi ve program kalitesinin değerlendirmesini sağlamak için programın değerlendirme işlemlerinin nasıl kullanılacağı konusunda gerekli olan eğitime sahip olması ve bunları sınıf uygulamalarını ve etkinlikleri uyarlamak için kullanması gerekmektedir. Özel gereksinimi olan çocukların ihtiyaçları ile ilgili bilgi ve beceri, aile merkezli uygulama, atipik gelişim ve yaygın sağlık sorunları, çocuk ve ailelerin ilgili yasalar altındaki hakları, bireysel eğitim planı ve bireysel aile hizmet planı ile ilgili rol ve sorumluluklar, katılımın desteklenmesi için stratejiler, bireysel ihtiyaçların karşılanmasını sağlayan programlar, materyaller ve uyarlama için stratejiler, sevk ve değerlendirme süreci, topluluk destekleri ve kaynakları konusunda gerekli mesleki eğitime sahip olması beklenmektedir (NAEYC, 2008a). 


\section{Öğretmen - Çocuk Oranı}

ABD’nin Massachusetts eyaletinde her çocuk grubunun bir öğretmeni bulunmaktadır ve gruptaki çocuk sayısına uygun olacak şekilde yardımcı öğretmen niteliğini taşıyan bir personel de sınıfta bulunmaktadır. Yardımcı öğretmen niteliği taşımayan kişiler, stajyer öğrenciler, gönüller ve aileler sınıfta bulunan personel-çocuk oranına dahil edilmemektedir. New York eyaletinde ise 18 veya daha az çocuklardan oluşan sınıflarda bir öğretmen ve bir yardımcı öğretmen olması gerekmektedir (Massachusetts Board of Education, 2005; New York City Department of Education, 2016).

National Association for the Education of Young Children'da belirtilen öğretmen çocuk oranları şunlardır; 0-15 aylık çocukların olduğu sınıflarda en az 6 en fazla 8 çocuk bulunması gerekmektedir. Sinıfta 6 çocuk olduğunda 1 öğretmene 3 çocuk, 8 kişi olduğu zaman 1 öğretmene 4 çocuk şeklinde (1:3 ya da 1:4) bir dağılım olması gerektiği belirtilmektedir. 12-28 aylık çocukların olduğu sınıflarda en az 6 en fazla 12 çocuk bulunması gerekmektedir. Bu yaş grubu için sınıftaki çocuk sayısının 10 olmasına izin verilmektedir fakat en iyi uygulama oranını sağlamak için sınıfta ek bir yetişkinin bulunması önerilmektedir. Bu yaş grubu için sınıfta 12 çocuk bulunması durumunda oran 1:4 olarak belirtilmektedir. 21-36 aylık çocukların oldukları sınıflarda en az 8 en fazla 12 çocuk olması gerekmektedir. 30-48 aylık çocukların olduğu sınıflarda en az 12 en fazla 18 çocuk, 48-60 aylık çocukların olduğu sınıflarda en az 16 en fazla 20 çocuk, 60 ay ve üzeri çocukların olduğu sınıflarda en az 16 ve en fazla 20 çocuk olması gerekmektedir. Herhangi bir devlet anaokulunda ya da özel anaokulunda ise 5 yaş çocukların olduğu sinıflardaki çocuk sayısı en az 20 en fazla 24 olarak belirtilmektedir (NAEYC, 2017a).

\section{Yardımcı Öğretmenin Denetimi ve Değerlendirilmesi}

Yardımcı öğretmenlerin görev ve sorumluluklarının belirlenmesinin önemli olduğu kadar çalışmalarını denetlemek ve değerlendirmek de aynı derecede önem arz etmektedir. Eğitimciler genellikle yardımcı öğretmenlerin denetimini yaparken bir yönetici de yardımcı öğretmenlerin değerlendirilmesini üstlenmektedir. Yardımcı öğretmenin denetimini yapacak kişinin, bir takımın parçası olarak çalışma yeterliliğine ve öğretim ekibinin profesyonel bir parçası olma becerine sahip olması gerekmektedir. Güven, iletişim, rollerin kesin olarak belirli olması, yönlendirmenin net bir şekilde yapılması, hedeflerin paylaşılma ve geri bildirim bir öğretim ekibinde olması gereken Özellikler arasında yer almaktadır. Öğretmenler, yardımcı öğretmenlerin denetlenmesi konusunda yeterli bilgi ve beceriye sahip olmayabilirler. Bu konu ile ilgili verilecek hizmet içi eğitimler yardım öğretmenlerin performansını arttırmak için faydalı olacaktır. Denetimden sorumlu olan kişi yardımcı öğretmenlerin danışmanıdır. Denetim sorumlusu, yardımcı öğretmenlerin eğitim ihtiyaçlarını anlamalı ve gerekli durumlarda ek mesleki eğitim için yardımcı öğretmenlerin yanında 
olmalı ve destek vermelidir. Öğretmenlerin ve yardımcı öğretmenlerin beceri, ilgi alanları, hobileri ve güçlü yanlarını ve bunlarla birlikte geliştirilmesi gereken alanlarını da birbirleriyle paylaşmaları için ortak bir zamana sahip olmaları faydalı olmaktadır. Yani öğretmenlerin, yardımcı öğretmenin görevlerinin belirlenmesi, planlama ve programı uygulama için denetleyici rolü üstlenmesi beklenmekte; yardımcı öğretmenlerin işe alınması ve işten çıkarılması gibi idari görevlerde yer alması beklenmemektedir. Ancak yönetici, yardımcı öğretmenlerin verimliliğini tam olarak göremeyebileceği için denetimden sorumlu olan kişi yani öğretmenler, değerlendirme konusunda yöneticiye yardımcı olmalıdır. Değerlendirme süreci ve araçları yardımcı öğretmenlik ile ilgili iş tanımına uygun şekilde geliştirilmeli ve yardımcı öğretmenlik pozisyonu için gereken yeterliliklere dayanmalıdır. Ayrıca değerlendirme süreci personelin performansları hakkında geri bildirim almaları ve buna bağlı olarak kariyer planlamaları yapmaları açısından faydalı olmaktadır (Connecticut State Department of Education, 2012).

Etkili denetimin önündeki engeller şu şeklide özetlenebilir (Virginia Department of Education, 2015);

- Yardımcı ögretmene yetersiz geri bildirim verilmesi ve bu geri bildirimlerin nesnel değil öznel olmasi.

- Yardımcı öğretmenin kurumsal bağlllık eksikliği.

- Öğretmenin ya da yardımcı öğretmenin denetleme konusundaki tutumlarının olumsuz olmasi.

- Rollerin farklı olmasına rağmen yardımcı öğretmenin veya öğretmenin rolünün eşit olduğu düşüncesine sahip olması roller arası çatışmaya neden olması.

- Etkili bir denetimi okulun örgütsel yapısının desteklememesi.

Yardımcı öğretmenlerin değerlendirmesinin amaçları şu şekilde özetlenebilir (Caruso ve Fawcett, 2006);

- Çocuklara verilen eğitim hizmetinin kalitesini arttırmak,

- Yeterlilikleri hakkında karar vermek,

- Programın hedeflere ulaşılmasını sağlamak,

- Gelişimlerini not etmek,

- Ödüllendirmek,

- Motive etmek,

- Öğretimlerini geliştirmelerine yardımcı olmak ve

- Gelecek için hedefleri belirlemek. 


\section{SONUÇ ve ÖNERİLER}

Yardımc1 öğretmenler, okul öncesi eğitim kurumlarında okul müdürü, müdür yardımcısı, okul öncesi öğretmeni, temizlik görevlisi ve diğer görevliler gibi çalışan, eğitim öğretim faaliyetlerinin tümünde öğretmene yardım eden bir personel olarak bulunmaktadır. Yardımcı öğretmenlikle ilgili olarak, ülkemizde henüz kamu kurumlarında bu uygulamanın yer almadığı, özel kurumlarda ise farklılıklar bulunmakla birlikte zaman zaman uygulandığı görülmektedir. Ancak diğer personelin görev ve sorumluluk tanımları yapılırken bu durumun yardımcı öğretmenler için geçerli olmadığı, farklı tanımların yapıldığı görülmektedir. Farklı ülkelerde de okul öncesi eğitimde yardımcı öğretmenin temel görev ve sorumluluklarında farklılıklar olduğu belirtilmektedir.

Literatür bilgisi ışığında bakıldığında; yardımcı öğretmenlerin eğitim düzeyinin, en az ortaöğretim veya ön lisans seviyesinde çocuk gelişimi olması gerektiği ya da çocuk gelişimi alanıyla ilgili sertifikaya sahip olmalanı gerektiği görülmektedir. Ön lisans mezunu olmayan yardımcı öğretmenlerin, çalıştıkları süre içerisinde örgün ya da yaygın eğitim kapsamında çocuk gelişimi ön lisans programlarına kayıt olması ve aktif olarak devam etmesini, yardımcı öğretmenlerin bilgi ve deneyimlerini destekleme noktasında etkili olacağı düşünülmektedir.

Yardımcı öğretmenlerin görev ve sorumlulukları, eğitim süreci, değerlendirme, aile katılımı, çocukların bakım ve ihtiyaçlarının karşılanması ve diğer işler olarak birkaç ana başlık altında toplanabilir. Görev ve sorumlukların tam olarak belirlenmesi, yardımcı öğretmenle okul öncesi öğretmenini ayıran sınırların çizilmesi, görev ve sorumluluk karmaşasının yaşanmaması için önemli görülmektedir. Görev ve sorumlulukların belirlenmesi yardımcı öğretmen ile okul öncesi öğretmenin birlikte daha verimli bir şekilde, bir ekip olarak çalışmasını sağlayabilir.

Yardımcı öğretmenin değerlendirilmesi okul yöneticileri tarafindan yapılmakta ve okul öncesi öğretmenlerinin de görüşleri alınmaktadır. Değerlendirme sürecinde yardımcı öğretmenin başarılı olduğu alanların ve desteğe ihtiyaç duyduğu alanların belirlenerek desteklenmesi ve mesleki kariyerinin gelişimine katkı sağlanmalıdır.

İleri araştırmalara ilişkin olarak da ülkemizde yardımcı öğretmenlik uygulamasının yapıldığı okul öncesi eğitim kurumlarında çalışanların konu ile ilgili görüş ve önerilerinin incelenmesini kapsayan nitel ve nicel çalışmalar önerilmektedir. 


\section{KAYNAKÇA}

Arizona Department of Health Services. (2010). Bureau Of Child Care Licensing Arizona Administrative Code And Arizona Revised Statutes For Child Care Facilities. http://www.azdhs.gov/licensing/childcare-facilities/index.php

Aslan, D. ve Köksal Akyol, A. (2006). Okul öncesi öğretmen adaylarının öğretmenlik mesleğine yönelik tutumları ve mesleki benlik saygılarının incelenmesi. Ç.Ü. Sosyal Bilimler Enstitüsü Dergisi, 15(2). s.51-60.

Aysu, B. (2007). Okul öncesi öğretmen adaylarının öğretmenlik mesleğine karşı tutumlarının incelenmesi. Ankara Üniversitesi. Fen Bilimleri Enstitüsü. Yayınlanmamış Yüksek Lisans Tezi.

Basford, E., Butt, G., \& Newton, R. (2017). To what extent are teaching assistants really managed?:'I was thrown in the deep end, really; I just had to more or less get on with it'. School Leadership \& Management, 37(3), 288-310.

Bellm, D., Burton, A., Whitebook, M., Broatch, L., \& Young, M. P. (2002). Inside the pre-K classroom: A study of staffing and stability in state-funded prekindergarten programs. Center for the Child Care Workforce.

Bursal, M. (2016). Temel Eğitim ve Ortaokul Öğretmen Adaylarının Öğretmenliğin İdeal Meslekleri Olmasına Göre Karşılaştırmalı Profilleri. Bayburt Eg̈itim Fakültesi Dergisi, 11(2).

Butt, R., \& Lowe, K. (2012). Teaching assistants and class teachers: Differing perceptions, role confusion and the benefits of skills-based training. International Journal of Inclusive Education, 16(2), 207-219.

Caruso, J. J., \& Fawcett, M. T. (2006). Supervision in early childhood education. Teachers College Press.

Cirhinlioğlu, Z. (1996). Meslekler ve sosyoloji. Gündoğan Yayınları.

Colker, L. J. (2008). Twelve characteristics of effective early childhood teachers. YC Young Children, 63(2), 68.

Connecticut State Department of Education. (2012). Guidelines for Training Support Of Paraprofessionals Working With Students Birth to 21. https://portal.ct.gov/$\angle$ media/SDE/Paraeducator/guidelines paraprofessionals.pdf

Çevik, O. \& Yiğit, S. (2009). Eğitim fakültesi öğrencilerinin profillerini belirlenmesi -Amasya Üniversitesi örneği-. C.Ü. Sosyal Bilimler Dergisi. 33(1) 89-106.

Department of Education of Training Queensland Goverment (2015). A guide for teacher aides: Ageappropriate pedagogies for the early years of schooling. https://qed.qld.gov.au/earlychildhood/about/Documents/pdf/guide-for-teacheraide.pdf

Ferguson, M. (2014). Teacher Aides: The Fine Art of Balance. Kairaranga, 15(2), 56- 63

Finn, J. D., \& Pannozzo, G. M. (2004). Classroom organization and student behavior in kindergarten. The Journal of Educational Research, 98(2), 79-92.

French, N. K., \& Gerlach, K. (1999). Topic\# 2 Paraeducators and teachers: Shifting roles. Teaching Exceptional Children,

Glenn, W. J., Moss, D. M., \& Schwab, R. L. (Eds.). (2005). Portrait of a profession: Teaching and teachers in the 21st century. Greenwood Publishing Group. 
Grisham-Brown, J., Pretti-Frontczak, K. (2003). Using planning time to individualize instruction for preschoolers with special needs. Journal of Early Intervention, 26, 31-46.

Gürkan, T. (2007). Öğretmen nitelikleri, görev ve sorumlulukları. A. Oktay \& Ö. P. Unutkan (Edt.) Okul öncesi eğitimde güncel konular, 124-137.

Jones, C. R., Ratcliff, N. J., Sheehan, H., \& Hunt, G. H. (2012). An analysis of teachers' and paraeducators' roles and responsibilities with implications for professional development. Early Childhood Education Journal, 40(1), 19-24.

Köroğlu A. Y. \& Göle M.O., (2020). Okul Öncesi Eğitim Kurumlarında Yardımcı Öğretmenlerin Görev ve Sorumluluklarına İlişkin Öğretmen Görüssleri. Uluslararası Erken Cocukluk Eğitimi Calısmalar Dergisi, 5:1, 16-28, DOI: 10.37754/658124.2020.512

Massachusetts Board of Education (2005). Early Childhood Program Standards For Three and Four Year Olds. bttps:// www.mass.gov/files/documents/2018/12/20/ta earlychildprogstan.pdf

Michigan State Board of Education (2017). CLASSROOM REQUIREMENTS Section: Classroom Requirements GSRP Implementation Manual Revised. https://www.michigan.gov/documents/mde/Classroom Requirements. August 20144 $\underline{66777 \text { 7.pdf }}$

National Association for the Education of Young Children [NAEYC] (2008a). Standard 6: Teachers A Guide to the NAEYC Early Childhood Program Standard and Related Accreditation Criteria. https://www.naeyc.org/sites/default/files/globallyshared/downloads/PDFs/accreditation/earlylearning/Standard $\% 206$ Teachers 2008 text.pdf

National Association for the Education of Young Children [NAEYC] (2008b). NAEYC definitions related to teaching staff members. http://www.naeyc.org/files/academy/file/DefinitionsOfTeachingStaff.pdf

National Association for the Education of Young Children [NAEYC] (2017a). NAEYC Early Learning Standards and Accreditation Criteria \& Guidance for Assessment. https: / www.naeyc.org/sites/default/files/globally-shared/downloads/PDFs/accreditation/earlylearning/Standards $\% 20$ and $\% 20$ Accreditation $\% 20$ Criteria $\% 20 \% 26 \% 20$ Guidance $\% 20$ for $\% 20$ Assess ment April\%202017 3.pdf

National Association for the Education of Young Children [NAEYC] (2017b). NAEYC Streamlined Accreditation Glossary of Terms, https://www.naeyc.org/sites/default/files/globallyshared/downloads/PDFs/accreditation/earlylearning/NAEYC $\% 20$ Streamlined $\% 20$ Accreditation $\% 20$ Glossary $\% 20$ of $\% 20$ Terms.pdf

Nebraska Department of Education. (2017). Approved Equivalency for Paraeducators in Early Childhood Programs Operated by Public Schools Districts or Educational Service Units https://www.education.ne.gov/wp-content/uploads/2017/07/para eq.pdf

New Hampshire Department of Health and Human Services. (2017). Child Care Program Teacher. https://www.nhes.nh.gov/elmi/products/licertocc/documents/ccpctea.pdf

New Jersey Department Of Education. (2015). Preschool Program Implementation Guidelines https://www.nj.gov/education/ece/guide/impguidelines.pdf

New York City Department of Education (2016). Pre-K for All Handbook 2016-17 for District Schools and Pre-K Centers. https:// infohub.nyced.org/docs/default-source/default-document-library/pre-kdistrict-schools-pre-k-centers-bandbook-2016-17.pdf 
New Zealand Government Ministry of Education (2012). The role of the teacher's aide https://parents.education.govt.nz/assets/Documents/Special-Education/The-role-ofthe-teachers-aide.pdf

Oklahoma Child Care Services (2018). Licensing requirements for child care centers. http://www.okdhs.org/OKDHS\%20Publication\%20Library/14-05.pdf

Pickett, A. L. (1999). Strengthening and supporting teacher/provider-paraeducator teams: Guidelines for paraeducator roles, supervision, and preparation. New York: National Resource Center for Paraprofessionals in Education and Related Services, Graduate Center, City University of New York. https:// files.eric.ed.gov/fulltext/ED440506.pdf

Puget Sound Educational Service District (2007). Paraeducator handbook. http://www.paraeducator.com/resources/parahandbook.pdf

Ratcliff, N. J., Jones, C. R., Vaden, S. R., Sheen, H., \& Hunt, G. H. (2011). Paraprofessionals in early childhood classrooms: an examination of duties and expectations. Early Years, 31(2), 163-179.

Shim, J., Hestenes, L., \& Cassidy, D. (2004). Teacher structure and child care quality in preschool classrooms. Journal of Research in Childhood Education, 19(2), 143-157.

Sosinsky, L. S., \& Gilliam, W. S. (2011). Assistant teachers in prekindergarten programs: What roles do lead teachers feel assistants play in classroom management and teaching?. Early Education \& Development, 22(4), 676-706.

U.S. Deparment of Healt and Human Services (2019). Head Start Policy \& Regulations, Sec. 648A Staff Qualifications and Development. https://eclkc.ohs.acf.hhs.gov/policy/head-startact/sec-648a-staff-qualifications-development

Virginia Department of Education, (2005). The virginia paraprofessional guide to supervision and collaboration with paraprofessionals: a partnership. https:/ / vouautismcenter.org/documents/va_doe_para_guide.pdf

Whitebook, M., Gomby, D., Bellm, D., Sakai, L., \& Kipnis, F. (2009). Preparing Teachers of Young Children: The Current State of Knowledge, and a Blueprint for the Future. Part I: Teacher Preparation and Professional Development in Grades K-12 and in Early Care and Education: Differences and Similarities, and Implications for ResearchPreparing. Center for the Study of Child Care Employment, University of California at Berkeley.

Wueste, D. E. (Ed.). (1994). Professional ethics and social responsibility. Rowman \& Littlefield.

Yilmaz, A. (2011). Reconstructing Teacher Identity: Experiences af a Turkish Teacher Aide in an American Preschool Classroom. Kastamonu Eğitim Dergisi. 19(3). 733-742.

Zembat, R. (2007). Okul öncesi eğitimde nitelik. A. Oktay \& ÖP Unutkean (Edt.) Okul öncesi eğitimde güncel konular. İstanbul: Morpa. 